\title{
OPTIMALITY THEORETICAL APPROACH IN RESOLVING VOCALIC HIATUS IN TIV LANGUAGE
}

\author{
Francis Iorchia Ayagah ${ }^{1}$ and Dr. (Mrs.) Elizabeth Ugechi \\ ${ }^{1}$ Department of Languages and Linguistics, Benue State University Makurdi \\ Email: talk2ayagah@gmail.com \\ ${ }^{2}$ Department of Languages and Linguistics, Benue State University Makurdi \\ Email: elizabethugechi@gmail.com
}

Cite this article:

Francis I.A., Elizabeth U. (2021), Optimality Theoretical Approach in Resolving

Vocalic Hiatus in Tiv

Language. International

Journal of Literature,

Language and Linguistics

4(1), 89-98. DOI:

10.52589/IJLLL-V5NYL142.

\section{Manuscript History}

Received: 17 Aug 2021

Accepted: 13 Sept 2021

Published: 22 Sept 2021

Copyright $(92020$ The Author(s). This is an Open Access article distributed under the terms of Creative Commons AttributionNonCommercial-NoDerivatives 4.0 International (CC BY-NC-ND 4.0 ), which permits anyone to share, use, reproduce and redistribute in any medium, provided the original author and source are credited.
ABSTRACT: This paper investigates vocalic hiatus resolution strategies in Tiv language. Hiatus is a phonological phenomenon whereby two vowel sounds occur in adjacent syllables with no intervening consonant. It is a dispreferred configuration in many languages but when it inevitably occurs, it is resolved through some of these strategies: epenthesis, vowel assimilation, vowel elision, secondary articulation, vowel coalescence, glide formation and diphthongization. Though there are other hiatus resolution strategies in Tiv, for want of time and space, this paper examines the most common ones: vowel assimilation and vowel elision, as hiatus resolution/repair strategies in Tiv, through the lenses of the Optimality Theory. It adopts a descriptive and analytical research design. The intuitive phonological ability of the researcher and oral interview through purposive sampling were used for eliciting data. Data were presented and analysed in tables. The study establishes the occurrence of vowel hiatus in Tiv. It demonstrates that vocalic hiatus is dispreferred in Tiv as it is in many other languages of the world. The study has shown that Tiv utilises inter-alia vowel assimilation and vowel elision to resolve vowel hiatus. The resolution is meant to ease articulation of Tiv words. Well-formedness of vowel configurations in Tiv was found to be constraint based in which case optimality of a candidate that undergoes repairs through either vowel assimilation or elision is determined by the ranking of the universal constraints that interact in the selection of candidates.

KEYWORDS: Vocalic Hiatus, Tiv Language, Resolution Strategies, Optimality Theory, Nigeria 


\section{INTRODUCTION}

Tiv is an agglutinative and tonal language which heavily relies on morpheme combination for derivational (both syntactic and morphological) as well as inflectional purposes. The coming together of morphemes very often results in various sound changes with varying grammatical effects. Most of the existing research works on Tiv language however are mainly devoted to morphology, phonology, syntax and semantics. There is therefore a general dearth of literature on the interfaces between the planes of linguistic analyses (particularly between morphology and phonology) and their implications on Tiv grammar. This research is intended to contribute to the documentation effort undertaken by scholars who are native speakers of the Tiv language. It is also intended to contribute to placing Tiv on the same pedestal of languages with formal descriptive analysis, within the ambit of the nature of linguistic theory.

Just like societies, every human language has a set of 'rules' or constraints which shape its realisation. When a morpho-syntactic or phonological context is created that does not adhere to these rules, some repair strategies are usually triggered to ensure that the structure adheres to the language's preferred structures. These processes are known as 'repair strategies' (Kager, 1999). This study aims to investigate the occurrence of vowel hiatus in Tiv, identify and describe strategies that are used in resolving vowel hiatus in the language. Analytical insights gleaned from Optimality Theory (OT) are utilised to account for hiatus resolution in Tiv.

\section{REVIEW OF RELATED LITERATURE}

Vowel hiatus is a term commonly used to refer to a sequence of adjacent vowels belonging to separate syllables (Casali, 1997). It is a phonological phenomenon whereby two vowel sounds occur in adjacent syllables with no intervening consonant. In other words, hiatus only occurs in between two juxtaposed syllables and not within a particular syllable. Siptar (2005:1) defines hiatus as "a heterosyllabic sequence of adjacent vowels which constitutes a dispreferred configuration in a number of languages." Siptar holds that some languages do not allow the occurrence of vowel hiatus; some prevent some instances of hiatus from occurring while other languages use some phonological strategies in resolving vowel hiatus.

A deduction from the above explanations points to a common viewpoint that hiatus only occurs in between two juxtaposed syllables and not within a particular syllable. It has often been observed that languages are generally quite intolerant of hiatus. For example, Kenstowicz (1994:23) notes that "vowel sequences (V + V) are phonologically unstable." Many languages of the world do not permit vowel hiatus and therefore make deliberate efforts to avoid it. But in cases where it is inevitable for hiatus to occur, it is resolved through some of the following processes/strategies: epenthesis, vowel assimilation, vowel elision, secondary articulation, vowel coalescence, glide formation and diphthong formation (Myers, 1987).

Even though hiatus is a universal phonological phenomenon, its repair strategies are language specific. This is because the occurrence of hiatus is not the same in all languages. However, each language that disallows hiatus resorts to some of the aforementioned strategies in resolving its occurrence. The difference in the choice of resolution strategies via a constraintbased analysis theory is referred to as cross-linguistic variation. This involves the use of a number of universal constraints hierarchically ranked in the order peculiar to individual languages to determine their violability. 
Phonologists have observed that languages of the world are generally quite intolerant of vowel hiatus. For instance, Kenstowicz (1994) and Trask (1996) note that vowel sequences V+V are phonologically unstable. Casali (2011) examines the place where hiatus occurs and establishes that the most common context where this happens is when an underlying vowel-final morpheme is directly followed by a vowel-initial morpheme. Two views have been presented in the literature regarding the force behind hiatus resolution. The first one is that vowel hiatus resolution strategies are driven by the need to avoid onsetless syllables. Scholars who hold this view are Brown (1970), Mtenje (1980), Shaw (1980), Katamba (1985), Pulleyblank (1986), Balogné Bérces (2006), and Sabao (2013). An alternative view is that hiatus resolution is derived by the need to avoid vowel sequences, and not by the requirement that all syllables have onsets (Orie \& Pulleyblank, 1998).

Trask (1997:65) justifies the need for employment of hiatus resolution strategies by saying that "such sequences are apparently uncomfortable, and languages employ a variety of strategies for repairing or eliminating the hiatus." It means therefore that when vowels come to meet at word and morpheme boundaries, that is when $\mathrm{V} \# \mathrm{~V}$ and $\mathrm{V}+\mathrm{V}$ sequences are created, "there is a marked predisposition for speakers to modify them in different ways so as to smooth out the articulatory transition" (Picard 2004:6). Casali (1996; 1997) takes an incursion into concatenative hiatus and concludes that "languages deal with sequences of vowels that arise through morphological and syntactic concatenation in various ways" (1997:497). Casari (1998) provides a list of the various sound changes as follows: Glide Formation/Syneresis, Vowel Assimilation, Elision/Deletion, Diphthongization and Coalescence. This work will select from this list the best strategies that will resolve hiatus in Tiv.

\section{Theoretical Framework}

This paper makes use of Optimality Theory (OT), which is a constraint based analysis, as its major theoretical framework. Optimality Theory is a theory of linguistic analysis that has its origin in a talk given by Alan Prince and Paul Smolensky at the Arizona Phonology Conference, University of Arizona in 1991 and later developed as an article in 1993. This theory emerged as a result of the dissatisfaction of some phonologists with the phonological theories at the time and the quest for a better and more efficient phonological theory. The theory proposes that the observed forms of language arise from the optimal satisfaction of conflicting constraints. This theory differs diametrically from other approaches to phonological analysis such as auto-segmental phonology and linear phonology which typically use rules rather than constraints. Constraints, according to Kager (1999:9), are structural requirements that the output form must conform to for it to be the optimal choice. Hence, the markedness value (which governs constraints) refers to the extent to which a linguistic structure is preferred (that which is unmarked) or dis-preferred (that which is marked) (Kager, 1999).

OT grammar contains several components: the lexicon which contains the original, unchanged underlying forms of the language, generate $(\mathrm{GEN})$, constraint $(\mathrm{CON})$, and evaluate (EVAL) (Kager, 1999). GEN, as the name suggests, generates an infinite number of output candidates from an input. These are evaluated by EVAL according to the CON which contains the set of universal constraints held cross-linguistically. Below is a representation of the structure of OT grammar according to Prince and Smolensky (1993:4): 
a. GEN $($ input $)=\{$ output 1 , output $2 \ldots$ output $3 \ldots\}$

b. EVAL (out $1, \mathrm{C} 1 \gg \mathrm{C} 2 \ldots)=$ optimal candidate

As mentioned earlier, the idea of markedness is central to this theory; however, a second idea is important to consider the idea of faithfulness. Faithfulness requires the output form to retain a number of phonological features as its input counterpart, as opposed to markedness, which refers to structural requirements (Kager, 1999). These constraints are in constant conflict because if you are to satisfy one, you will inevitably violate another. Kager (1999) states that there are no exclusive constraints that refer to the input only; however, faithfulness constraints consider both the input and the output. An OT analysis is presented using tables, as seen in Table (i) below. In OT tables, constraints are placed in the first row; a solid line (and [^]) represents domination, while a dashed line (and a comma) represents equally-ranked constraints. The input form is placed in the first cell prior to the constraints. The output candidates are placed below the input. These candidates are subject to the EVAL which subjects them equally to the constraints. A fatal violation is marked using (*!), a non-fatal violation with $(*)$, and the optimal candidate with the pointer ( ).

Constraint Ranking: Constraint $\mathrm{A}$ » Constraint $\mathrm{B}$ » Constraint $\mathrm{C}$ » Constraint $\mathrm{D}$

Table 1: Optimality theory example

\begin{tabular}{|c|l|l|l|l|}
\hline Input & $\begin{array}{l}\text { Constraint A } \\
\text { Highest-ranked }\end{array}$ & Constraint B & Constraint C & $\begin{array}{l}\text { Constraint D } \\
\text { Lowest-ranked }\end{array}$ \\
\hline a. Candidate & $* !$ & & & $*$ \\
\hline b. Candidate & & $* !$ & $*$ & $*$ \\
\hline c. Candidate & & & & $*$ \\
\hline
\end{tabular}

Source : (Kager, 1999)

From table 1 above, we can see that Candidate 1 fatally violates Constraint $\mathrm{A}$ and Candidate 2 fatally violates Constraint B; they are therefore eliminated. Candidate 3 non-fatally violates the lowest-ranking constraint to best satisfy higher-ranking constraints, and is therefore the optimal candidate.

It has to be noted that Gen, Eva and Con are not the same at all instances. This is because language constituents or environments in which linguistic constraints appear varies. The selection of Eva and Con is based on the type of Gen and environment.

\section{METHODOLOGY}

This paper adopts a descriptive and analytical research design. The instruments of data collection for the study include the intuitive phonological ability of the researcher as a native speaker of the language. The researcher also orally interviewed competent native speakers, linguists, academics and other critical stakeholders of the Tiv language. Because Tiv is a homogenous language, this study covers only Tiv speakers in Benue State. The study did a purposive sample of 150 competent native speakers who were deemed proficient in the language. These include 50 adults or elderly speakers, 20 clergymen, 50 academics as well as 
30 members of Tiv Language Studies and Development Association (TLSDA). The rationale behind the choice of these persons is that they are believed to be competent native speakers who possess an appreciable level of proficiency and competence in the language. The presentation of data is done in tables and the study employs Optimality Theory to analyse the strategies that are used in resolving hiatus in the Tiv language.

\section{DATA PRESENTATION, ANALYSIS AND DISCUSSION OF FINDINGS}

\section{Vowel Assimilation in Tiv}

Vowel assimilation is a process through which a neighbouring vowel segment is made similar or more similar to another vowel by duplicating a phonetic feature (Dirven, 2004). Assimilation can occur either within a word or between words. It occurs in normal speech, and it becomes more common in rapid speech. There are three main types of assimilation: progressive and regressive. Regressive assimilation occurs when the vowel that undergoes a change (target vowel) precedes the vowel that triggers the change. This type of vowel assimilation is however none existent in Tiv as evidenced in the data collected. Progressive assimilation on the other hand occurs when the target vowel comes after the trigger vowel as shown in example (1-4) below:

\begin{tabular}{|c|c|c|c|}
\hline \multirow[t]{2}{*}{ 1. à.dô.à.ya } & / àdo & + aya/ & $\rightarrow$ àdôôya \\
\hline & Hamlets & & \\
\hline \multirow[t]{2}{*}{ 2. á.tô.á.kàà } & /atô / & + aka:/ & átôôkàa \\
\hline & Reasons & & reasons \\
\hline \multirow[t]{2}{*}{ 3. a. tô.a. tyev } & /ato & + atyev / & atôôtyev \\
\hline & Foreigners & & foreigners \\
\hline \multirow[t]{2}{*}{ 4. a.ve.a.ve } & /ave & + avel & $\rightarrow$ aveeve \\
\hline & now & now & now \\
\hline \multirow[t]{2}{*}{ 5. á.ve.á.har } & lave/ & + har & $\rightarrow$ aveehar \\
\hline & Hands & two & two hands \\
\hline \multirow[t]{2}{*}{ 6. á.to.á.tár } & /ato & + atar/ & $\rightarrow$ ávéetar \\
\hline & Ears three & & three ears \\
\hline \multirow[t]{2}{*}{ 7. á.ko.á.hè } & /ako & + ahel & $\rightarrow$ ákóohe \\
\hline & Batteries & new & new batteries \\
\hline
\end{tabular}




\begin{tabular}{|c|c|c|c|}
\hline \multirow[t]{2}{*}{ 9. á.mo.á. hàr } & /amo & + ahar/ & $\rightarrow$ ámoohár \\
\hline & songs & two & two songs \\
\hline 10. á.to.á. ior & /ato & + ior/ & atooior \\
\hline
\end{tabular}

As it is one of the characteristics of Bantu languages, Tiv is a morphologically agglutinating language - inflectional and derivational morphology and other word formation processes are done by concatenating morphemes onto root or existing words together. Reduplication and compounding are very common word formation processes. It is worth pointing out that most hiatus in Tiv language occur at the boundaries of two words which are formed through compounding or reduplication, as shown in examples 1-10 above.

In analysing vowel assimilation within OT, this paper adopts marked constraint on directionality of vowel assimilation by Sasa $(2006$; 2009) as shown in (a) and (b) below:

a) SPREAD[F]-L: If a vowel feature $[\mathrm{F}]$ is associated with a vowel on the right, the same feature is associated with an adjacent vowel to the left.

b) SPREAD[F]-R: If a vowel feature $[\mathrm{F}]$ is associated with a vowel on the left, the same feature is associated with an adjacent vowel to the right.

Satisfaction and violation of the constraints (a) and (b) above are determined by the kind of assimilation under analysis. Therefore, the ranking of the constraints in (a) and (b) above depends on whether assimilation is progressive or regressive.

Assimilation is also considered in the Optimality Theory as a process that requires a segment within the phonological or morphological domain to agree on some features, and any feature disagreement or disharmony within the domain is attributed to the restrictions set by markedness constraint (Cole \& Kisserberth, 1995; Padgett, 1995). Constraint driving assimilation across an oral segment is satisfied at the cost of violating faithfulness constraint that works in favour of correspondence between input and output (Padgett, 1995). This paper adopts the models of faithfulness constraint by Beckman (1998) and Sasa (2001), as stated in (c) below:

c) IDENT[F]: The vowel segments in the output must have the same specification as their input correspondents in the features.

In Tiv, faithfulness constraint as in (c) above has to be ranked relatively very low to allow assimilation to take place in order to repair vowel hiatus.

*HIATUS >> SPREAD[F]-R > SPREAD[F]-L > > IDENT[F] 
Table 2: Constraints interaction in working out the best candidate in progressive assimilation within a word in Tiv

\begin{tabular}{|c|l|l|l|l|}
\hline Candidates & $*$ HIATUS & SPREAD[F $\}-R$ & SPREAD[F]-L & IDENT[F] \\
\hline a) adôaya & $* !$ & $* !$ & $* !$ & $* !$ \\
\hline b) adoya & & $*$ & $*$ & $*$ \\
\hline c) adôôya & & & $* !$ & $*$ \\
\hline
\end{tabular}

From table 2 above, candidate (a) woefully fails optimal test by fatally violating the highest ranking constraint - the markedness constraint *HIATUS, and all the other constraints. Candidate (b) violates alignment constraint SPREAD $[\mathrm{F}\}-\mathrm{R}$ which is ranked second among the competing constraints. It also violates all other constraints except *HIATUS and is thus eliminated. Candidate (c) is optimized because it satisfies all the high ranking constraints that other candidates do not.

\section{Vowel Elision}

In Tiv, hiatus situations can be resolved by deleting V1 in some contexts and V2 in other contexts. This means that there is both V1 and V2 elision in Tiv depending on the context. Elision is one of the several strategies used for resolving hiatus when it is created through morpheme concatenation. It is used for removing offending configurations. Vowel elision is occasioned by the fact that (a) smoothness of speech is difficult to come by in languages where vowel elision does not exist. (b) Vowel elision applies in normal rapid speech, which means that learners of such languages, especially children growing up in the language must be able to reconstruct individual lexical items from the highly deformed phonological structure to be able to compute the meaning of such a string. Vowel Elision may target either the leftmost vowel in a sequence (henceforth V1) or the rightmost (henceforth V2). Below is the data collected on vowel elision in Tiv. This work adopts the following constraint models for analysis of vowel Elision in Tiv.

NOHIATUS: The sequence of two vowels (V1.V2) is prohibited (Mudzingwa, 2013);

ONSET: Every syllable must have an onset (Prince \& Smolensky, 1993);

ANCHOR-L: The leftmost root node of a morpheme in the input must have an output correspondent (V2 deletion is prohibited) (Mudzingwa \& Kadenge, 2011);

MAX-IO(RT): Every input root node has an output root node (Mudzingwa, 2010);

MAX-IO( $\mu$ ): Every input mora has an output mora correspondent (Mudzingwa, 2013; Rosenthall, 1997).

Examples V1 elision

V1 ELISION:

11. pà.sé. á.vé

$$
\mathrm{C}<\mathrm{V} 1>\mathrm{V} 2 \mathrm{CV}
$$$$
+ \text { ave } / \rightarrow
$$

hands

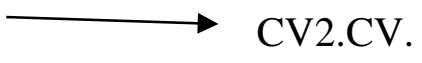

pàsáve

loose hands 
12. kón.dò .ató $\quad /$ kondo + ato/ $\rightarrow$ kóndato

Deaf ears deaf ears

13. kén.dè,a.na $/$ kende + ana/ $\rightarrow$ kéndàna

lift him lift him

14. a. yàn.gé .à.fà /yange $\quad+$ afa/ $\rightarrow$ yàngáfà

time will know it will be known with time

15. vàn.de. á.nà /Vande $\quad+$ ana $\rightarrow$ vàndánà

Before him before him

Table 3: Constraints interaction in working out the best candidate in elision of V1 as contained in 11-15 above.

\begin{tabular}{|c|l|l|l|l|l|}
\hline \multicolumn{2}{|l|}{ INPUT } & \multicolumn{2}{l|}{ OUTPUT } & \multicolumn{2}{l|}{} \\
\hline PASEAVE & NOHIATUS & ONSET & ANCHOR-L & MAX-IO $(\mathrm{RT})$ & MAX-IO $(\mu)$ \\
\hline a) Paseave & $* !$ & $*$ & $*$ & $*$ & $*$ \\
\hline b) Paseve & & & $* !$ & $*$ & $*$ \\
\hline c) Pasave & & & & $*$ & $*$ \\
\hline
\end{tabular}

In Table 3, candidate (a) violates the highest constraint - the markedness constraint which prohibits the occurrence of a sequence of two vowels in adjacent syllables and also violates all the constraints generated by input. Candidate (b) violates three of the ranking constraints and thus is second to candidate (a) in terms of constraints violation and failure of optimal test. Candidate (c) satisfies all the constraints that the other candidates do not satisfy and is therefore selected as the optimal candidate.

Examples of vowel 2 elision

V2 Elision: $\mathrm{CV} 1<\mathrm{V} 2>\mathrm{CV} \longrightarrow \mathrm{CV} 1 . \mathrm{CV}$

16. kù.lé .a.ve /kule $\quad+$ ave / $\rightarrow$ kùléve

Clap hands clap hands

17. kùn.de .á.tùu /kunde + atuu:/ $\rightarrow$ kùndétùu

Cook okro cook okro 
18. ti.lè. á.nà $\quad /$ tile $\quad+$ ana/ $\rightarrow$ tílèna

Stand with him stand with him

19. bén.dè. ámo / bende $\quad+\mathrm{amo} / \rightarrow$ béndèmo

Touch me touch me

20. te.ma.i.nyá /tema $\quad+$ inya/ $\rightarrow$ temanya

sit down sit down

\begin{tabular}{|c|l|l|l|l|l|}
\hline \multicolumn{2}{|l|}{ INPUT } & \multicolumn{2}{l|}{ OUTPUT } & \multicolumn{2}{l|}{} \\
\hline KULEAVE & NOHIATUS & ONSET & ANCHOR-R & MAX-IO(RT) & MAX-IO $(\mu)$ \\
\hline a) Kuleave & $* !$ & $*$ & $*$ & $*$ & \\
\hline a) Kulave & & & $* !$ & $*$ & $*$ \\
\hline c) Kuleve & & & & $*$ & $*$ \\
\hline
\end{tabular}

Table 6 above shows that candidate (a) violates the highest constraint which is the markedness and thus fails the optimality test. Candidate (b) exhibits non-correspondence in the mora affiliation of the input and the output thus violating the highly ranked constraint-IDENT- $\mu$. This leads to its disqualification. Candidate (c) satisfies all the constraints that the other candidates do not satisfy and is therefore selected as the optimal candidate.

\section{CONCLUSION}

It has been demonstrated in this paper that vocalic hiatus is dispreferred in Tiv as it is in many languages of the world. The paper has shown that Tiv utilises inter-alia vowel assimilation and vowel elision to resolve vowel hiatus. The resolution is meant to ease articulation of Tiv of words. Well-formedness of vowel configurations in Tiv was found to be constraint based in which case optimality of a candidate that undergoes repairs either through vowel assimilation or elision is determined by the ranking of the universal constraints that interact in the selection of candidates.

\section{REFERENCES}

Beckman, J. N. (1998). Positional faithfulness. Unpublished PhD Dissertation, University of Massachusetts, Amherst.

Casali, R . 1992. Vowel Elision, Glide Formation, and Syllabification in Niger-Congo languages. MS, Summer Institute of Linguistics and Ghana Institute of Linguistics, Literacy, and Bible Translation.

Casali, R. (1988). Vowel clusters and syllable structure. In Kofi Saah \& Emmanuel Osam (Eds.) Nawuri: Papers in Ghanaian Linguistics 7:40-61. Legon: Institute of African Studies, University of Ghana. 
Casali, R. (1994). Vowel Elision and Glide Formation in Niger-Congo: A Harmony Theoretic Approach. Paper presented at the January 1994 LSA meeting, Boston, January 9, 1994.

Casali, R. 1995a. Patterns of Glide Formation in Niger-Congo: An Optimality Account. Paper presented at the January 1995 LSA meeting, New Orleans, January 7, 1995. 139

Casali, R.(1996). Resolving hiatus. Doctoral Dissertation, University of California, Los Angeles.

Casali, R.(1997) Vowel elision in hiatus contexts: Which vowel goes? Language 73:493-533. University of California Los Angeles. K

Casali, R.F. 1998. Resolving hiatus. New York: Garland.

Cole, J. \& Kisserberth, C. (1995). Nasal harmony in optimal domain theory. In V. Samiian and J. Schaeffer (eds.). Proceedings of the Western Conference of Linguistics (WECOL), Vol.7, 44-58. Fresno CA: California State University and Fresno.

Dirven, R. (2004). Cognitive Exploration of Language and Linguistics. University of Duisbur Kager,R. (1999) Optimality Theory. Cambridge: Cambridge University Press.

Katamba, F. (1985). A non-linear account of the syllable in Luganda. In Didier L. Goyvaerts (ed). African Linguistics: Essays in memory of M.W.K. Semikenke (Studies in the sciences of language, 6.). Amsterdam: John Benjamins Publishing Company. 267-283.

Mtenje, A. (2007) On recent trends in phonology: vowel sequence in Bantu languages. Soars Working Papers in Linguistics. 15 (2007):33 48.

Mudzingwa, C. (2010). Shona morphophonemics: Repair strategies in Karanga and Zezuru. Unpublished PhD Dissertation, University of British Columbia.

Mudzingwa, C. (2013). Hiatus resolution strategies in Karanga (Shona). Southern African Linguistics and Applied Language Studies. 31(1): 1-240

Mudzingwa, C., \& Kadenge, M. (2011). Comparing Hiatus Resolution in Karanga and Nambya: An Optimality Theory Account. Nordic Journal of African Studies. 20(3): 203-340.

Myers, S.P. (1997). OCP effects in Optimality Theory, Natural Language and Linguistic Theory, Vol.15, No.4, 847-892.

Padgett, J. (1995). Feature classes. In University of Massachusetts Occasional Papers in Linguistics 18: Papers in Optimality Theory, (ed.), by J. Beckman, L. Walsh, Dickey \& Suzanne Urbanczyk, 385-420. Amherst: GLS

Prince, A. \& Smolensky, P. (1993) Optimality Theory: constraint interactive in Generative Grammar. Ms Rutgers University, New Brunswick and University of Colorado, Boulder.

Pulleyblank, Douglas. (1988). Vowel deletion in Yoruba. Journal of African Languages and Linguistics 10:117-136.

Pulleyblank,. (1986). Underspecification and low vowel harmony in Okpe. Studies in African Linguistics.

Rosenthall, S. 1997. The distribution of prevocalic vowels. Natural Language \& Linguistic Theory. 15(1): 139-180.

Sasa, T. (2006). Directionality in harmony: a case study of Pulaar. Paper presented at the 14th Mid Continental Workshop on Phonology, Minneapolis, MN.

Shaw, P. (1980). Theoretical issues in Dakota phonology and morphology. New York: Garland Publishing.

Siptar, P. (2005) Hiatus resolution in Hungarian: an optimality theoretic account. An abstract for ICSH 7. 